\title{
The brine shrimp Artemia: adapted to critical life conditions
}

\author{
Gonzalo M. Gajardo ${ }^{1 *}$ and John A. Beardmore ${ }^{2}$ \\ ' Laboratorio de Genética, Acuicultura \& Biodiversidad, Departmento de Ciencias Básicas, Universidad de Los Lagos, Osorno, Chile \\ 2 School of Medicine, Swansea University, Swansea, UK
}

\section{Edited by:}

Zbigniew R. Struzik, The University of

Tokyo, Japan

\section{Reviewed by:}

Jun Wang, Nanjing University of Posts and Telecommunications, China

Moacir Fernandes De Godoy,

Medicina de São José do Rio Preto,

Brazil

\section{${ }^{*}$ Correspondence:}

Gonzalo M. Gajardo, Laboratorio de Genética, Acuicultura \& Biodiversidad, Departmento de Ciencias Básicas,

Universidad de Los Lagos, Avd.

Fuchslocher 1305, Osorno, Chile.

e-mail:ggajardo@ulagos.cl
The brine shrimp Artemia is a micro-crustacean, well adapted to the harsh conditions that severely hypersaline environments impose on survival and reproduction. Adaptation to these conditions has taken place at different functional levels or domains, from the individual (molecular-cellular-physiological) to the population level. Such conditions are experienced by very few equivalent macro-planktonic organisms; thus, Artemia can be considered a model animal extremophile offering a unique suite of adaptations that are the focus of this review. The most obvious is a highly efficient osmoregulation system to withstand up to 10 times the salt concentration of ordinary seawater. Under extremely critical environmental conditions, for example when seasonal lakes dry-out, Artemia takes refuge by producing a highly resistant encysted gastrula embryo (cyst) capable of severe dehydration enabling an escape from population extinction. Cysts can be viewed as gene banks that store a genetic memory of historical population conditions. Their occurrence is due to the evolved ability of females to "perceive" forthcoming unstable environmental conditions expressed by their ability to switch reproductive mode, producing either cysts (oviparity) when environmental conditions become deleterious or free-swimming nauplii (ovoviviparity) that are able to maintain the population under suitable conditions. At the population level the trend is for conspecific populations to be fragmented into locally adapted populations, whereas species are restricted to salty lakes in particular regions (regional endemism). The Artemia model depicts adaptation as a complex response to critical life conditions, integrating and refining past and present experiences at all levels of organization. Although we consider an invertebrate restricted to a unique environment, the processes to be discussed are of general biological interest. Finally, we highlight the benefits of understanding the stress response of Artemia for the well-being of human populations.

Keywords: Artemia, animal extremophile, evolution, adaptation, salty lakes, stressful environments

\section{INTRODUCTION}

Because the processes of life are complicated there is no simple solution to the problem of surviving, as individuals and species, the unpredictable challenges that environments pose to populations. Human-induced perturbations (Allendorf and Hard, 2009; Darimont et al., 2009; Stenseth and Dunlop, 2009) have increased environmental uncertainty, greatly compromising species, ecosystem resilience, and the ability to withstand such perturbations (Berkes et al., 2003). Both natural (evolutionary) and unnatural (human-driven) forces are constantly putting pressure on populations and species to evolve toward new adaptive peaks or fitness optima (Schuler and Conte, 2009). Iconic examples of humaninduced impacts are biodiversity and habitat loss (see biodiversity outlook 3), introduction of exotic species that end-up as pest (Garcia de Leaniz et al., 2010) and modification of animal behavior and human-wildlife interactions-brought about by urbanization (Ditchkoff et al., 2006) and climate change (Thuiller, 2007). The "fight or flight" response of humans (males mainly) is a classical behavioral and physiological response to a threat, be it a predator or a natural disaster, that activates a complex cascade of events (McEwen, 2007). In urban modern life, social factors, life events, and illness are causally related and therefore stress is considered a general adaptation syndrome (Rabkin and Struening, 1976; McEwen, 2007).

Adaptation means stability in a given environment at any particular time, a state reached by evolutionary change on organismal attributes, from gene to phenotypes, led by Natural Selection. Locally adapted or ecologically divergent populations are the first step to a journey leading to new species, a major component of biodiversity. Adaptation is a complex response to environmental changes or threats that encompasses past and present experiences imprinted in the genome that cannot be understood by its component parts alone. As a matter of fact, it involves a highly interactive network of events at different hierarchical levels, from individuals, populations, and species to ecosystems (Terradas and Peñuelas, 2009; Bard, 2010). For example, although morphology and other life history traits are tested first by natural selection, "bodies express ecology" suggest Piersma and van Gils (2011), the gene-phenotype relationship is equally complex with pleiotropic and epigenetic effects as examples of genomic events interacting with the environment at different levels in the network (Dowell et al., 2010). Phenotypes also reflect historical solutions to environmental pressures, explaining why certain phenotypic responses become inefficient under rapidly changing conditions. 
This article addresses the complex adaptive response evolved by the brine shrimp Artemia (Crustacea, Anostraca) to thrive in hypersaline lakes (from here onward referred as salty lakes), a "forbidden environment" for most organisms (Eads, 2004). Indeed, Artemia is the sole macro-planktonic inhabitants of salty lakes, and hence a good example to discuss what is critical for life, the subject of this issue. The two relevant elements of the evolutionary process and adaptation are dissected: the environment and the organism itself (see Figures 1 and 2). Sadly, the biology, geology, chemistry, and hydrography of salty lakes are all poorly known and one reason for this is their commonly remote locations, particularly those inland, whilst the most visited ones have rarely been monitored on a regular basis, with the exception of the Great Salt Lake in Utah, USA, where Artemia is commercially exploited, chiefly for aquaculture purposes (Dhont and Sorgeloos, 2002) to be described here later. Based on the available information on natural sites (Lenz and Browne, 1991; Trianthaphyllidis et al., 1998; Van Stappen, 2002), laboratory-based experiments and records obtained from artificial environments like salt ponds, reasonable information, albeit imperfect, exists on the range of environmental conditions experienced by Artemia (life box, sensu Wharton, 2007).

For the organism, we review the suite of adaptations expressed at different domains (molecules, cells, organs, individuals, and populations) to understand how they account for the complex adaptive phenotype that is generated and maintained by natural selection, though sometimes Artemia populations experience cycles of expansion and contraction favoring drift. In other words, we attempt to integrate what textbooks show in independent disciplinary chapters (see for example Abatzopoulos et al., 2002). "Nothing makes sense in biology except in the light of evolution" said Dobzhansky (1973), and within this conceptual framework it is clear that complex responses to challenging environments began from simpler ones as Darwin stated ("descent with modification"), in a process that follows simple natural rules: the gradual accumulation of randomly generated variations due to mutations, constantly sorted out by natural selection (Avise and Ayala, 2009). Mutations are the chance (random) component of evolution, a concept coined by Monod (1971), see also Ayala (2009), that set the stage for the action of natural selection which plays, instead, the deterministic (necessity) role of selecting favorable variations available at a given time and place (differential reproduction). Hence, randomly produced mutations play an innovative role by producing evolutionary novelties. But since such novelties appear at a slow pace, evolution is seen as a slow process by the synthetic theory of evolution, the leading conceptual framework until today (but see an alternative view in Dean and Thorton, 2007). However, the wealth of molecular information now available has shown that the innovation process can be greatly accelerated by new genomic events such as incorporation of alien genes (gene replacement) or even entire organisms, whilst epigenetic events modify the ability of the genome to perform its various functions (Ryan, 2006; Terradas and Peñuelas, 2009; Staples et al., 2010; see

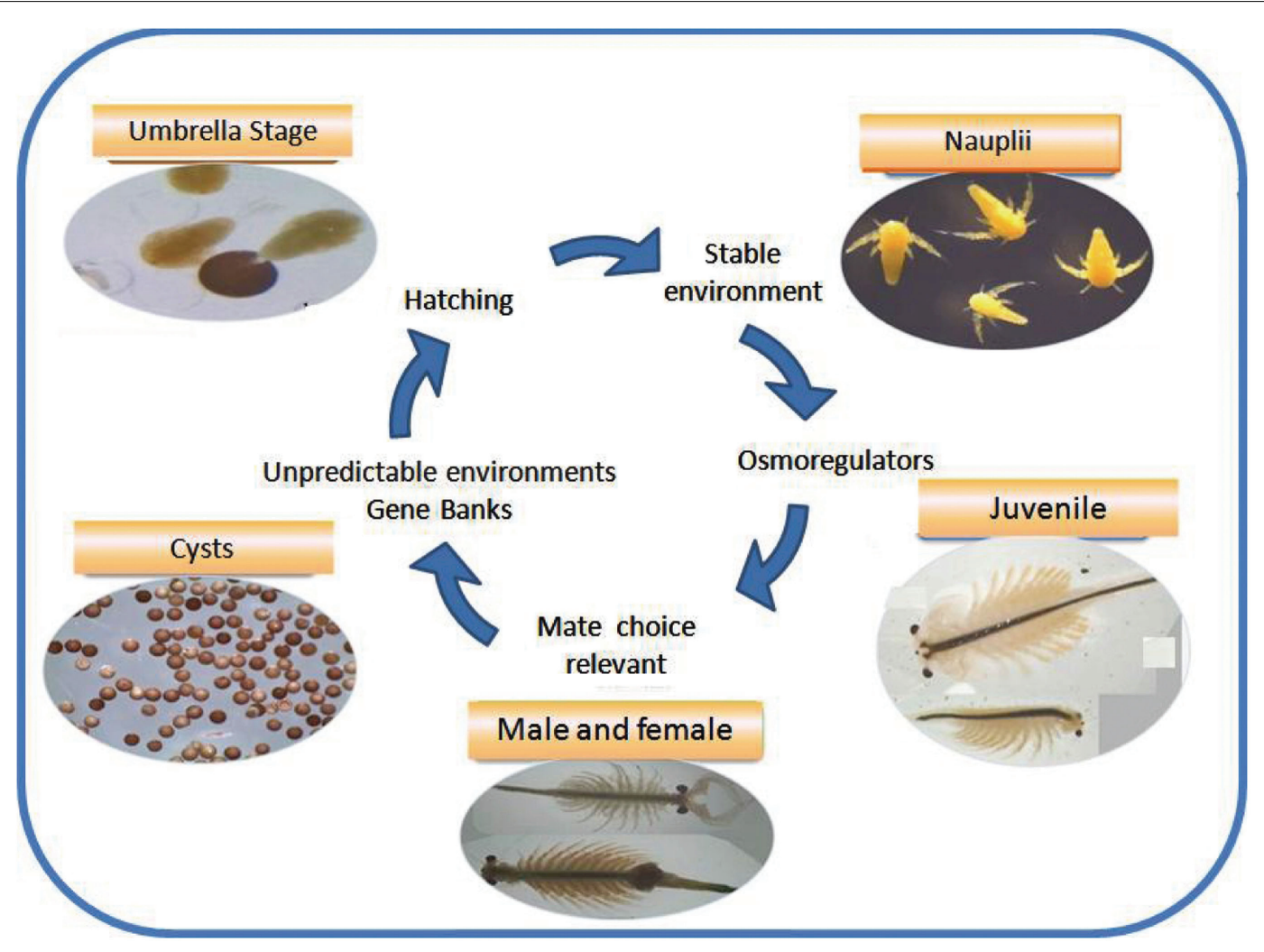

FIGURE 1 |The life cycle of a salty survivor: the extremophile Artemia. Different stages of the cycle are actively involved in survival and reproduction under critical environmental conditions. 


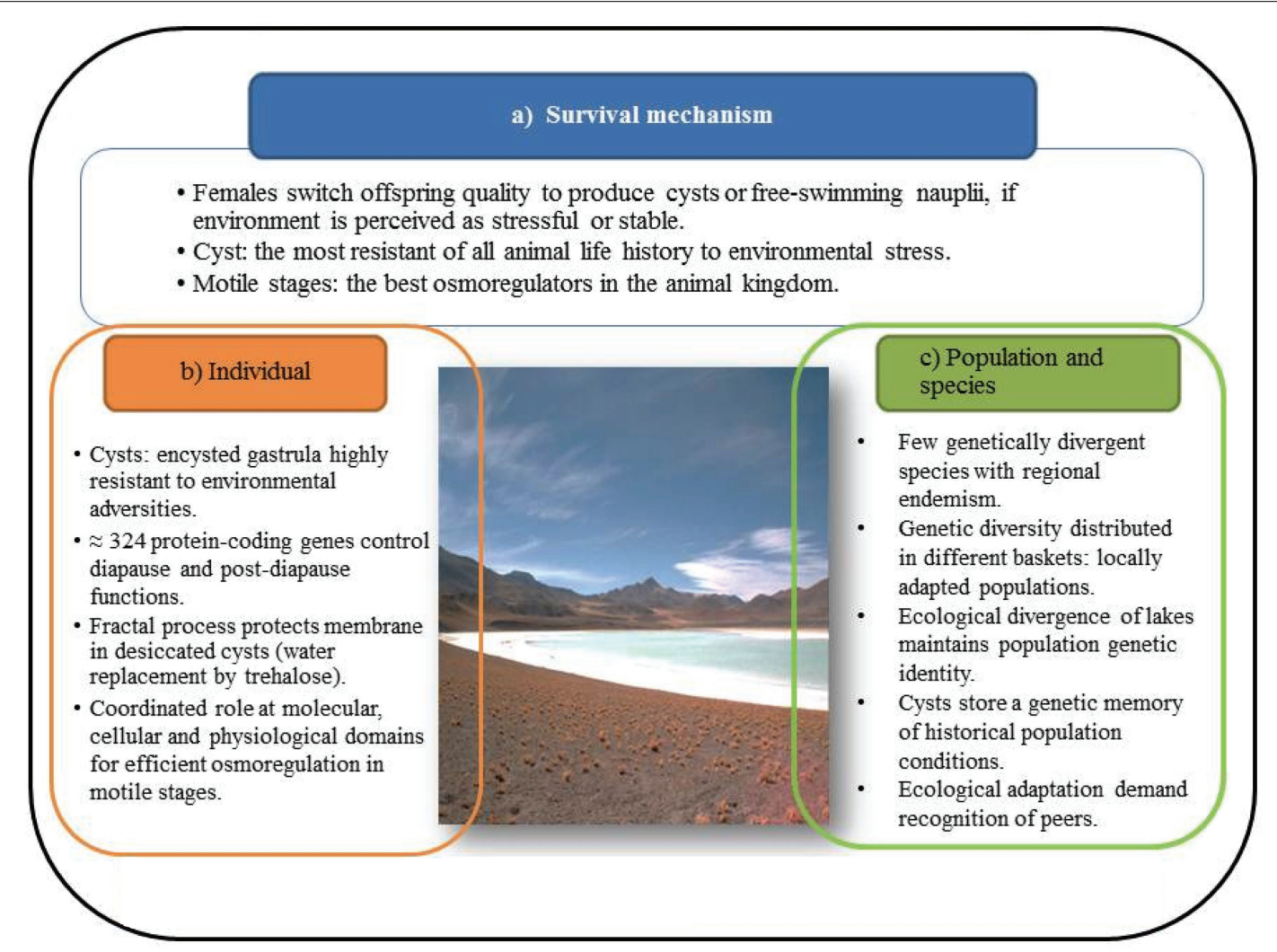

FIGURE 2 | Salty lakes impose critical conditions on reproduction of individuals, populations, and species. Adaptation to such conditions has evolved a network of different functional and hierarchical domains.

also Shapiro, 2011 for an updated review on how bacteria studies have contributed to new insights on evolution). It is also known that some genes are more prone to mutate than others (Stern and Orgogozo, 2009). The interaction of the resulting novelties within populations modifies selection rates; hence, ecological divergence can lead to reproductive isolation (speciation) in relatively short times (Hendry et al., 2007).

\section{SALTY LAKES, ONLY FOR SALT-LOVERS}

Hypersaline lakes are distributed in all continents even in the Antarctic, mostly in tropical and sub-tropical areas where solar radiation is high enough to favor high evaporation rates which are required to maintain high salt concentration. But striking exceptions exist, such as the very high altitudes of Chile and Tibet. There are currently about 500 sites were Artemia has been reported (Van Stappen, 2002) but it is certain that many more exist around the world. Their recognition as extreme ecosystems becomes evident from their low eukaryotic biodiversity, to the point that, in a few cases, Artemia is the only macroscopic representative. Hence, Artemia is rightly referred to as a model animal extremophile or "halophile" (salt-lover; Wharton, 2007), whilst the relatively high prokaryotic biodiversity observed in salty lakes (DasSarma and Arora, 2001; Demergasso et al., 2004) indicates different evolutionary capabilities or strategies in these organisms. Salty lakes with Artemia are, therefore, considered good biodiversity laboratories due to their simple web structure (Gajardo et al., 2006).
Nevertheless, Artemia tolerates very well the very large environmental variations that exist in many salty lakes, achieving very large population sizes. The range of environmental variation is due in some degree to latitude and the associated climatic conditions. Some salty lakes are permanent, where Artemia flourish year-round, while others are seasonal and dry-out in a predictable or unpredictable manner (Lenz and Browne, 1991). Some locations are coastal or thalassohaline ( $\mathrm{NaCl}$ major salt) while others are far inland, athalassohaline (rich in anions other than chloride), such as those that are found at $4,500 \mathrm{~m}$ above sea level in the Tibetan Plateau. This area has been recently highlighted as the "third pole" because it has the third largest reserve of ice on earth after the Arctic and Antarctic, and it is alarming that the ice is melting quickly (Qiu, 2008). Closer to the stratosphere than any other Artemia site, this is a special location subject to high UV radiation and peculiarly cold for its latitude. In the Tibet area around 352 saline lakes exist (Van Stappen, 2002). By contrast at the other extreme of the globe, the Atacama Desert in Chile is one of the driest areas in the world, and Artemia is found there at about 2,500 $\mathrm{m}$ altitude in a unique environmental setting (Gajardo and Beardmore, 1993; Demergasso et al., 2004). In contrast to the melting down of ice in the Tibet by indirect human causes like climate change, salty lakes in the Atacama Desert are increasingly perturbed by water drainage associated with mining activities (deposits of $\mathrm{NaCl}$ and lithium salts). Two other quite unusual Artemia locations are found in Chilean Patagonia (Amarga and 
Cisnes lagoons; Gajardo et al., 1999, 2002; Clegg and Gajardo, 2009; Beristain et al., 2010) that experience severe weather conditions, rather unusual for Artemia standards (cold, rainy, and extremely windy). To complete this very brief account of Artemia environmental variability, there are also man-made salt ponds or salinas, where salt is produced by evaporation of seawater, and where Artemia can exist in certain salty ponds that approach the precipitation point of $\mathrm{NaCl}, 340 \mathrm{~g} \mathrm{~L}^{-1}$ (Clegg and Trotman, 2002). However, in order for Artemia reproduction to occur the salinity must be well below that, although still very high.

Characteristic examples of natural lakes are found in Asia in areas such as China, Tibet, Iran, and Kazakhstan. All these contain four of the seven sexual Artemia species currently known, making evident both the peculiarities of salty lakes and the ecological divergence or specificity of Artemia species. The Mediterranean area, where Artemia probably originated, contains the fifth sexual species (Abreu-Grobois and Beardmore, 1982; Abreu-Grobois, 1987; Gajardo et al., 2002; Van Stappen, 2002; Baxevanis et al., 2006), and the other two species are found in Lake Grassmere in New Zealand, Chaplin Lake in Canada, the Great Salt Lake in Utah, USA, and the already mentioned Chilean sites. These are just examples - there are many other cases.

Although salinity seems to be the major driver of Artemia distribution, other critical factors are particularly severe in specific areas, as evidenced above. Most of them have synergistic effects, difficult to evaluate in nature, but amenable to study under laboratory conditions (Lenz and Browne, 1991). Salinity, ionic composition and temperature are the critical factors highlighted by Van Stappen (2002), whilst Hebert et al. (2002) additionally considers UV radiation as being of utmost evolutionary importance, since it increases mutation rates, the novelty factor, and/or the raw material, on which natural selection acts. Accordingly, Hebert et al. (2002) observed higher rates of DNA sequence divergence in the halophilic Anostraca from Australia and North America compared to their fresh-water relatives (Daphniids).

For the purpose of this article we group these critical factors as follows:

(i) Reversible stressors, when reaching the upper or lower limit tolerated by Artemia (temperature and salinity).

(ii) Mutagenic stressors, affecting DNA replication fidelity (ionic composition and UV light, but salt concentration plays a role as well). On the positive side they could generate variability (new functional variants), whilst their negative effects are filtered out by selection.

Salinity ranges widely (1-mM-5 M) (Hebert et al., 2002) because of latitudinal variation and other considerations, and so Artemia can be found with other planktonic animals at lowmedium salinities. The optimum is estimated under laboratory conditions at $60 \mathrm{~g} \mathrm{~L}^{-1}$ in experiments where several fitness parameters were compared (Lenz and Browne, 1991), the maximum being close to $\mathrm{NaCl}$ saturations in solar ponds $\left(340 \mathrm{~g} \mathrm{~L}^{-1}\right)$, whilst the lower limit depends on the upper salinity tolerance of fish predating on Artemia, in extreme cases being as high as 100$130 \mathrm{~g} \mathrm{~L}^{-1}$ as reported by Van Stappen (2002). As it will be shown later in Section "Artemia: A Survival Machine" Artemia has evolved efficient solutions to these challenges, from molecules to fractal physiological processes (see also Figure 2). A major impact of high salinity is osmotic stress, desiccation, low oxygen tension, increased metabolic rate to cope with the high energy demand required to maintain the osmoregulatory system at full capacity, and alteration of DNA-protein relationship that lowers DNA replication fidelity (Hebert et al., 2002).

The temperature box ranges widely $\left(5-40^{\circ} \mathrm{C}\right)$, the lower limit being consequences of the extreme habitats already discussed such as those in the Tibetan Plateau, Atacama Desert, and Patagonia, in northern and southern Chile, respectively. The upper limit is often seen in man-made salinas where Artemia thrives in shallow ponds. The optimal temperature for at least some species of Artemia has been established at about $25^{\circ} \mathrm{C}$ (Lenz and Browne, 1991; Van Stappen, 2002), but extremely high temperatures can overlap the effects of extreme salinity that drastically reduce the size of Artemia populations. Extremely low temperatures, including freezing, are overcome by the production of encysted embryos (see below). Depending on the prevailing anions, salty lakes are classified as chloride, sulfate, or carbonate-rich, including the possibility of combinations of two or even three major anions. Variation in ionic composition is therefore wide and likely the highest among metazoans (Cole and Brown, 1967; Van Stappen, 2002).Ultraviolet light is normally high in salty lakes as these are mainly located in areas of high solar radiation, but it is particularly high in those at high altitude due to the reduction in stratospheric ozone. UV radiation reduces metabolic activity and induces the formation of dimers of DNA more efficiently at $254 \mathrm{~nm}$. UV-B $(280-320 \mathrm{~nm})$ produces irreversible damage and death, and the effect is greater in naupliar stages than adult (lower LD50; Dattilo et al., 2005). The ability to repair such mutations explains, in part, differential survival observed between individuals and populations.

In addition to the molecular-cellular and physiological impact of these stressors on individuals, there can be population/species effects such as ecological divergence (Schuler and Conte, 2009). This has been recognized as a speciation mode in Artemia by Abreu-Grobois (1987), Mono Lake in California, USA, a carbonate-rich lake described as an evident example of ecological isolation (Browne and Bowen, 1991).

\section{HOW MANY ARTEMIA SPECIES ARE THERE?}

Gajardo et al. (2002, p. 226, Table 1) listed some of the attributes that make Artemia a good model to study adaptation and speciation. This organism is also considered a paradigmatic species in understanding the evolutionary biology of arthropods and related groups (Marco et al., 1991; Chen et al., 2009). A look at the existing Artemia species and their distribution shows three striking facts in which the species (life history and genetic background) and the environment are tightly linked:

(1) there are six sexual species, a relatively low number, most of them geographically restricted to salty lakes in specific regions in Eurasia (regional endemism) at, or close to, the Mediterranean area where Artemia species diverged from the ancestral species some 80 million years ago (Baxevanis et al., 2006). These are the so-called Old World species: 
Artemia urmiana (Günther, 1890), Lake Urmi, Iran, where there are also parthenogenetic populations. But also the species would be present in Ukraine.

Artemia tibetiana (Abatzopoulos et al., 1998, 2003), Tibetan Plateau.

Artemia sinica (Cai, 1989), PR of China, and Mongolia. Artemia salina (Leach, 1819), Mediterranean Basin.

Artemia sp. Kazakhstan (Pilla and Beardmore, 1994), since only a single sample from Kazakhstan was studied the specific status is still under discussion.

(2) There are parthenogenetic populations as well, as indicated above, and these originated in multiple events in Central Asia either from A. urmiana or the Kazakhstan population (Muñoz et al., 2010), and probably from all of the sexual species indicated above (Baxevanis et al., 2006). Parthenogens would have migrated to the Mediterranean Basin where a dramatic salinity increase and habitat subdivision (Abreu-Grobois, 1987) would have facilitated their expansion, very likely in the form of cysts (Muñoz et al., 2010). The estimated time for the appearance of asexual forms varies according to the genetic markers and the methodology of analysis considered: three MYA (Baxevanis et al., 2006), 40 MYA (Badaracco et al., 1987) or very recently (Muñoz et al., 2010). The importance of unusual habitats (different from those occupied by parental sexual species) seems essential for the generation and maintenance of a parthenogenetic mode (Muñoz et al., 2010), and also is evident from the fact that parthenogenetic forms tend to co-exist, and even displace sexuals under special conditions (Amat et al., 2005).

(3) Two species are found in the Americas (New World species): A. franciscana and $A$. persimilis, the former widely divergent from the Old World species (Gajardo et al., 2002), though some similarity with all Asian species and parthenogens has been found by comparing mitochondrial ITS1 sequences and 16 S RFLP markers (Baxevanis et al., 2006). A. persimilis is closer to Old World species, in fact it is the most widely divergent of all Artemia species as determined by the use of different genetic markers (Gajardo et al., 2002; Baxevanis et al., 2006; Muñoz et al., 2008; Kappas et al., 2009), and is restricted to southern latitudes in South America, particularly Argentina and Chile. Although bar coding and other genetic markers are useful for assessing genetic distance between species, data of this nature need to be viewed with some caution, taking into account recent observations showing that not all genes are equal in the light of evolution. In other words, evolutionarily relevant mutations tend to accumulate in hotspot genes and at specific locations within genes (Stern and Orgogozo, 2009). Having said that, we note that $A$. franciscana has a very distinctive feature separating it from all other species. This feature is its chromo centre number, i.e., highly repetitive heterochromatin, which is known to play a role in chromosome segregation and reorganization, nuclear and cellular organization, and regulation of gene expression (MacGregor and Sessions, 1986; see Hayden, 2010, for humans). Thus, noncoding regions matter significantly, and because of that it is highly relevant to note that this trait varies significantly with latitude in A. franciscana (Gajardo et al., 2001), the most widely distributed species (also found invading non-native areas like the Mediterranean, Amat et al., 2005). Due to its repetitive nature, heterochromatin is prone to expansions and contractions (Parraguez et al., 2009, and references therein), thus representing an opportunity for rapid genomic change.

\section{ARTEMIA: A SURVIVAL MACHINE}

The suite of responses Artemia has evolved to cope with the harsh conditions imposed by salty lakes is schematically shown in Figure 1. The most visible response is the ability of females of all species, including parthenegenetic forms, to switch reproductive mode, or offspring quality (Gajardo and Beardmore, 1989), depending on whether the environment is perceived as stable, generally the case of permanent lakes, or stressful, like seasonal lakes that dry-out. Lack of food, low oxygen tension, extremely high or low salinity and temperature (even lack of available mates) are stressors as well. In the first case females produce predominantly offspring in the form of free-swimming nauplii (ovoviviparity) or as cysts (oviparity). We subscribe to the statement of Clegg and Trotman (2002) that cysts are "the most resistant of all animal life history stages to environmental stress," at least based on the experience with A. franciscana, the most studied species, whilst motile stages (nauplii and other larval stages and adults) are "the best osmoregulators in the animal kingdom." Both life history stages are schematically treated in the "organism" compartment of Figure 2, but also because they have different adaptive repertoires as they are programmed to face different environmental conditions as indicated above. Salty lakes modulate also the population and species compartment (Figure 2). With regard to organisms, there are 324 protein-coding genes associated with diapause and post-diapause influencing cell components, molecular functions, such as antioxidant activity that protect desiccated cysts from molecular oxygen, and biological processes like development, growth, response to stimulus and interaction between individuals, as reported by Chen et al. (2009). Some of these proteins are stored in cysts and utilized after their reactivation, or are involved in antidesiccation and diapause mechanisms. Just to mention a few of them: cathepsin-like cysteine proteinase involved in yolk utilization in embryos, proteases, protease inhibitors, and chaperones $(p 26, \mathrm{Hsp} 70)$ that prevent protein aggregation. In stressed cells, Hsp70 and p26 move to the nucleus to stabilize matrix proteins. Maintaining cell membrane fluidity (or prevent it from vitrification) in the encysted embryo by means of the sugar trehalose (Clegg and Trotman, 2002) involves critical fractal physiological processes that protect from the destructive effects of dehydration, chiefly through its ability to serve as a substitute for structural water associated with the membrane surface. Likewise, adaptation of nauplii to brine is another magnificent process that began to be studied long ago (Croghan, 1958a,b). It is achieved by maintaining hemolymph at concentrations and compositions considerably lower and qualitatively different from the external hyperosmotic medium and this requires retaining or taking up water, while excess ions are eliminated to the medium against huge concentration gradients (reviewed by Clegg and Trotman, 2002).The key component in this ion-transporting process in larval stages is the salt gland and its enzyme $\mathrm{Na}$, K-ATPase that first appears in emerged embryos, increases dramatically as the larvae hatch and pass through the 
first instar epithelia of animals in general (Conte, 1984). High salinity imposes the extra challenge of reduced dissolved oxygen, hence efficient oxygen uptake (Dwivedi et al., 1987) becomes vital to avoid impairment of critical functions such as swimming and feeding. As salinity increases and oxygen tension diminishes, hemoglobin synthesis increases. However, respiratory rates differ between nauplii and adults, and between females and males, a process mediated by three hemoglobin types, resulting from the permutation of subunits $\alpha$ and $\beta$, differing in their oxygen affinity, and so affecting the physiological response to oxygen availability (Clegg and Trotman, 2002).

With regard to the population and species compartment (Figure 2), the most striking phenomenon here is that overall high genetic diversity (see Gajardo et al., 2002; Baxevanis et al., 2006; Muñoz et al., 2010) of the species is heterogeneously distributed over the different component populations. In other words, the species gene pool is distributed over different safety baskets along the distribution range. Such ecological divergence is the mode of speciation evolved by the group as proposed by AbreuGrobois and Beardmore (1982) and Abreu-Grobois (1987), see also Gajardo et al. (2002). Ecologically adapted populations retain local adaptations in a process modulated by differential selective pressures of each environment. Local populations are caused by geographic isolation of the island-like nature (Gajardo et al., 2002) of salty lakes that restrict gene flow mediated by water birds, the natural cyst dispersers together with wind. Cycles of extinction and re-colonization, expansion and contraction, observed in seasonal lakes or ponds that dry-out, are also significant drivers of genetic differentiation. Such ecological specificity has trade-offs, the price paid is isolation and solitude; in other words, Artemia is prevented from interaction with other species, for good or bad. There would be restrictions between populations as well, as reported by Rode et al. (2011). These authors performed crosses between females and males hatched from cysts collected at different times, and found that females survived better and had longer inter brood intervals when mated with their contemporary males compared to when they were mated with males from the future or the past. A similar example in Drosophila showed that females adapted to specific ecological conditions, and therefore with a particular bacterial composition in the gut, mate preferentially with males with the same similar gut composition (Sharon et al., 2010).

\section{ARTEMIA, STRESS, AND SOCIETY}

Response to stressful situation maximizes fitness advantages of animals in nature, survival, behavior, and reproduction being the obvious outcome. Artemia for example is an example of stress response of an animal low in the tree of life that, however, exhibits similarities to humans that are up in the biological hierarchy making evident that evolution builds complex solutions from simpler ones, and such solutions heavily depend on the complexity of the environment. The Artemia environment is relatively simple in terms of the number of known stressors or stresses affecting it, though it is clear the environment is multidimensional. Instead, the human physical and cultural environment has evolved faster than adaptation to them, and the consequence is a maladaptive response or disease (adaptation syndrome; see McEwen, 2007). Alike Artemia, the brain plays a key role in coordinating the behavioral and physiological response to stressors. Another striking phenomenon is the ability of Artemia females to recognize and select peers as a way to maintain ecological adaptation, which is somewhat found in humans as well.

Finally, understanding the mechanisms of adaptation to stressful environments in Artemia has some indirect benefits to human societies because of the role it plays in the aquaculture of marine fish and crustaceans (Dhont and Sorgeloos, 2002). Larval stages of some of these species cannot utilize pelleted first feed but need a live diet. Artemia larvae (which can be nutritionally enhanced) provide not only basic nutritional requirements but also enzymes and other valuable dietary elements as well forming an attractive prey for predatory fish larvae. Artemia production is a highly profitable industry. In the developed world cysts are harvested from sites such as the Great Salt Lake in Utah and after canning and vacuum packing are sold in quantity worldwide. In developing nations such as Vietnam and Thailand, cheaper cysts are produced in artisanal saltworks.

\section{CONCLUDING REMARKS}

As a major macro-faunal inhabitant of salty lakes, the brine shrimp Artemia provides a unique example of how to develop a strategy in dealing with critical conditions needed for survival. Being adapted to the harsh conditions that salty lakes impose on survival and reproduction of individuals, but also on populations and species, constitutes a complex evolutionary response that integrates different levels of biological organization. Such a highly integrated response has evolved from more simple solutions in a process that requires the constant availability of innovations (through mutation and other genomic events) and the filtering process of natural selection. The relatively high diversity of prokaryotic life in salty lakes is an example of simpler though extremely successful solutions, but also the co-existence of sexual species and parthenogenesis in Artemia, shows the importance of variation in reproductive modes for evolution to proceed. Parthenogenesis has been successful under certain environmental conditions, some of which remain in certain areas or lakes as to allow this reproductive mode to persist. The long time co-existence of parthenogens and the sexual species from which they originated, is a phenomenon that some biologists (at least of those working on salty lakes) find it difficult to accept considering the widespread adoption of sexual reproduction by most taxa.

The following aspects of salty lakes and the extremophile Artemia, the two relevant actors in our evolutionary play, are highlighted in this article:

1. Salty lakes offer a quite restrictive range of ecological conditions, salinity being often recognized as a critical stressor. However, additional stressors such as specific ionic conditions also favor the differentiation of locally adapted populations (ecological isolation) that thrive in chloride, carbonate, or sulfate-rich lakes. A better characterization of salty lakes should provide further details on how adaptation proceeds in Artemia.

2. The ability of females to "perceive" forthcoming environmental difficulties is amazing though it is an example of the signaling process species have evolved through a highly interactive and dynamic process. This is yet a field to be explored. 
3. The ability of females to switch offspring quality, i.e., to produce cysts or nauplii, is a good example of the importance of the above (2). Cysts and nauplii are equipped with a differential suite of adaptations to cope with the environment immediately ahead, in the case of nauplii (often a stable one), or in relatively uncertain immediate environments or that to be faced in the years to come (Rode et al., 2011).

4. Cysts are arguably the most resistant of all animal life history forms to environmental stress, whilst motile stages (nauplii, larval stages, adults) are the best osmoregulators in the animal kingdom as stated by Clegg and Trotman (2002). Cysts are gene banks that store a genetic memory of historical population conditions, but also are survival vehicles. They aid in the dispersal of Artemia, but also are reservoirs of genetic variability (Gajardo and Beardmore, 1989), the fuel for evolutionary change and resilience.

5. There are few genetically divergent Artemia species restricted to specific regions (regional endemism), but highly divergent

\section{REFERENCES}

Abatzopoulos, T. J., Beardmore, J. A., Clegg, J. S., and Sorgeloos, P. (2002). Artemia: Basic and Applied Biology. Dordrecht: Kluwer Academic Publishers.

Abatzopoulos, T. J., Zhang, B., and Sorgeloos, P. (1998). Artemia tibetiana: preliminary characterization of a new Artemia species found in Tibet (People's Republic of China). International Study on Artemia. LIX. Int. J. Salt Lake Res. 7 , 41-44.

Abatzopulos, T. J., Kappas, I., Bossier, P., Sorgeloos, P., and Beardmore, J. A. (2003). Genetic characterization of Artemia tibetiana (Crustacea: Anostraca). Biol. J. Linn. Soc. Lond. 75, 333-344.

Abreu-Grobois, F. A. (1987). "A review of the genetics of Artemia," in Artemia Research And Its Applications, eds P. Sorgeloos, D. Bengtson, W. Decleir, and E. Jaspers (Wetteren: Universa Press), 61-99.

Abreu-Grobois, F. A., and Beardmore, J. A. (1982). "Genetic differentiation and speciation in the brine shrimp Artemia," in Mechanisms of Speciation, ed. C. Barigozzi (New York: Alan R. Liss), 345-376.

Allendorf, F. W., and Hard, J. J. (2009). Human-induced evolution caused by unnatural selection through harvest of wild animals. Proc. Natl. Acad. Sci. U.S.A. 106, 9987-9994.

Amat, F., Hontoria, F., Ruiz, O., Green, A. J., Sánchez, M. I., Figuerola, J., and Hortas, F. (2005). The American brine shrimp as an exotic invasive species in the western Mediterranean. Biol. Invasions 7, 37-47.
Avise, J. C., and Ayala, F. J. (2009). In the light of evolution III: two centuries of Darwin. Proc. Natl. Acad. Sci. U.S.A. 106, 9933-9938.

Ayala, F. J. (2009). Darwin and the scientific method. Proc. Natl. Acad. Sci. U.S.A. 106, 1033-1039.

Badaracco, G., Baratelli, L., Ginelli, E., Meneveri, R., Plevani, P., Valsasnini, P., and Barigozzi, C. (1987). Variations in repetitive DNA and heterochromatin in the genus Artemia. Chromosoma 95, 71-75.

Bard, J. (2010). A systems biology view of evolutionary genetics. Bioessays 32, 559-563.

Baxevanis, A. D., Kappas, I., and Abatphylogenetics and asexuality in the brine shrimp Artemia. Mol. Phylogenet. Evol. 40, 724-738.

Beristain, P., Gajardo, G., and Bossier, P. (2010). Species-specific RFLP pattern in the heat shock protein26 gene (Hsp26): a single-locus tool for species identification and experimental testing of habitatinduced isolation in the new world Artemia species. Mol. Ecol. Resour. $10,229-231$.

Berkes, F., Colding, J., and Folke, C. (2003). Navigating Social-Ecological Systems: Building Resilience for Complexity and Change. Cambridge: Cambridge University Press.

Browne, R. A., and Bowen, S. T. (1991). "Taxonomy and population genetics of Artemia," in Artemia Biology, eds R. A. Browne, P. Sorgeloos, and C. N. A. Trotman (Boca Raton: CRC Press), 221-235. zopoulus, T. J. (2006). Molecular

populations adapted to the specific ecological conditions of salty lakes (see 1). Hence, it seems the strategy of the species to persist is to distribute the gene pool in different baskets (salty lakes) that are well adapted to more specific conditions.

6. To avoid loss of these adaptations by genetic flux (a role attributed to water birds and wind), the island-like nature (geographical isolation), and the local ecological pressures in particular prevent immigrants from surviving and, therefore, prevent or limit cross-breeding.

\section{ACKNOWLEDGMENTS}

This paper is dedicated to Professor Patrick Sorgeloos, who retires in 2013, as a mark of recognition of the immense contributions he has made to knowledge of the biology and sustainable exploitation of Artemia. Professor James S. Clegg and Dr. Gilbert Van Stappen made very useful comments, and Margarita Parraguez helped with the figures. Support from FONDEF D09I1256 (Chile) is gratefully appreciated.

Cai, Y. (1989). A redescription of the brine shrimp (Artemia sinica). J. Biol. 47, 105-110.

Chen, W. H., Ge, X. M., Wang, W. W., Yu, J., and Hu, S. N. (2009). A gene catalogue for post-diapause development of an anhydrobiotic arthropod Artemia franciscana. BMC Genomics 10, 52. doi:10.1186/1471-2164-10-52

Clegg, J. S., and Gajardo, G. (2009). Two highly divergent new world Artemia species, A. franciscana and A. persimilis from contrasting hypersaline habitats express a conserved stress protein complement. Comp. Biochem. Physiol. 153, 451-456.

Clegg, J. S., and Trotman, C. (2002) "Physiological and biochemical aspects of Artemia ecology," in Artemia Basic and Applied Biology, eds T. J. Abatzopoulos, J. A. Beardmore, J. S. Clegg, and P. Sorgeloos (Dordrecht: Kluwer Academic Publishers), 129-170.

Cole, G. A., and Brown, R. J. (1967). The chemistry of Artemia habitats. Ecology 48, 858-861.

Conte, F. P. (1984). Structure and function of the crustacean larval salt gland. Intern. Rev. Cytol. 91, 45-106.

Croghan, P. C. (1958a). The survival of Artemia salina (L.) in various media. J. Exp. Biol. 35, 213-218.

Croghan, P. C. (1958b). The mechanism of osmotic regulation in Artermia talina (h.): the physiology of the branchiae. J. Exp. Biol. 35, 234-242

Darimont, C. T., Carlson, S. M., Kinnison, M. T., Paquet, P. C., Reimchen, T. E., and Wilmers, C. C. (2009). Human predators outpace other agents of trait change in the wild. Proc. Natl. Acad. Sci. U.S.A. 106, 952-954.

DasSarma, S., and Arora, P. (2001). Halophiles. Encyclopedia of Life Sciences. London: Nature Publishing Group.

Dattilo, A. M., Bracchini, L., Carlini, L., Loiselle, S., and Rossi, C. (2005) Estimate of the effects of ultraviolet radiation on the mortalityof Artemia franciscana in naupliar and adult stages. Int. J. Biometeorol. 49, 388-395.

Dean, A. M., and Thorton, J. W. (2007). Mechanistic approaches to the study of evolution: the functional synthesis. Nat. Rev. Genet. 8, 675-688.

Demergasso, C., Casamayor, E. O. Chong, G., Galleguillos, P., Escudero, L., and Pedrós-Alió, C. (2004). Distribution of prokaryotic genetic diversity in athalassohaline lakes of the Atacama Desert, northern Chile. FEMS Microbiol. Ecol. 48, 57-69.

Dhont, J., and Sorgeloos, P. (2002). "Applications of Artemia," in Artemia: Basic and Applied Biology, eds T. J. Abatzopoulos, J. A. Beardmore, J. S. Clegg, and P. Sorgeloos (Dordrecht: Kluwer Academic Publishers), 251-277.

Ditchkoff, S. S., Saalfeld, S. T., and Gibson, C. J. (2006). Animal behavior in urban ecosystems: modifications due to human-induced stress. Urban Ecosyst. 9, 5-12.

Dobzhansky, T. (1973). Nothing in biology makes sense except in the light of evolution. Am. Biol. Teach. 35, 125-129. 
Dowell, R. D., Ryan, O., Jansen, A., Cheung, D., Agarwala, S., Danford, T., Bernstein, D. A., Rolfe, P. A., Heisler, L. E., Chin, B., Nislow, C., Giaever, G., Phillips, P. C., Fink, G. R., Gifford, D. K., and Boone, C. (2010). Genotype to phenotype: a complex problem. Science 328, 469.

Dwivedi, S. N., Diwan, A. D., and Iftekhar, M. B. (1987). Oxygen uptake in the brine shrimp Artemia in relation to salinity. Ind. J. Fish. 34, 359-361.

Eads, B. D. (2004). Salty survivors. J. Exp. Biol. 207, 1757-1758.

Gajardo, G., Abatzopoulos, T. J., Kappas, I., and Beardmore, J. (2002). "Evolution and speciation," in Artemia Basic and Applied Biology, eds T. J. Abatzopoulos, J. A. Beardmore, J. S. Clegg, and P. Sorgeloos (Dordrecht: Kluwer Academic Publishers), 225-250.

Gajardo, G., and Beardmore, J. A. (1989). Ability to switch reproductive mode in Artemia is related to maternal heterozygosity. Mar. Ecol. Prog. Ser. 56, 191-195.

Gajardo, G., Beardmore, J. A., and Sorgeloos, P. (2001). International study on Artemia. LXII: genomic relationships between Artemia franciscana and Artemia persimilis, inferred from chromocenter numbers. Heredity 87, 172-177.

Gajardo, G., Mercado, C., Beardmore, J. A., and Sorgeloos, P. (1999). International study on Artemia. LX. Allozyme data suggest that a new Artemia population in southern Chile (5029'S; 7345'W) is A. persimilis. Hydrobiologia 405, 117-123.

Gajardo, G., Sorgeloos, P., and Beardmore, J. A. (2006). Inland hypersaline lakes and the brine shrimp Artemia as simple models for biodiversity analysis at the population level. Saline Syst. 2:14. doi: 10.1186/1746-1448-2-14

Gajardo, G. M., and Beardmore, J. A. (1993). Electrophoretic evidence suggests that the Artemia found in the Salar de Atacama, Chile, is A. franciscana Kellog. Hydrobiologia 257, 65-71.

Garcia de Leaniz, C., Gajardo, G., and Consuegra, S. (2010). From best to pest: changing perspectives on the impact of exotic salmonids in the Southern Hemisphere. System. Biodivers. 8, 447-459.

Günther, R. T. (1890). Crustacea in contributions to the natural history of Lake Urmi, N. W. Persia and its neighbourhood (zoology). J. Linn. Soc. Lond. 27, 394-398.

Hayden, E. C. (2010). Life is complicated. Nature 464, 664-667.

Hebert, P. D. N., Remigio, E. A., Colbourne, J. K., Taylor, D. J., and Wilson, C. C. (2002). Accelerated molecular evolution in halophilic crustaceans. Evolution 56, 909-926.

Hendry, A., Nosil, P., and Rieseberg, L. (2007). The speed of ecological speciation. Funct. Ecol. 21, 455-464.

Kappas, I., Baxevanis, A. D., Maniatsi, S., and Abatzopoulos, T. J. (2009). Porous genomes and species integrity in the branchiopod Artemia. Mol. Phylogenet. Evol. 52 192-204.

Leach, W. E. (1819). Entomostraca. Dictionaire des Science Naturelles 14, 524.

Lenz, P., and Browne, R. (1991). "Artemia Ecology," in Artemia Biol$o g y$, eds R. A. Browne, P. Sorgeloos, and C. N. T. Trotman (Boca Raton, FL), 237-254.

MacGregor, H. C., and Sessions, S. K. (1986). The biological significance of variation in satellite DNA and heterochromatin in newts of the genus Triturus: an evolutionary perspective. Philos. Trans. R Soc. Lond. B Biol. Sci. 312, 243-259.

McEwen, B. S. (2007). Physiology and neurobiology of stress and adaptation: central role of the brain. Physiol. Rev. 87, 873-904.

Marco, R., Garesse, R., Cruces, J., and Renart, J. (1991). “Artemia molecular genetics," in Artemia Biology, eds R. A. Browne, P. Sorgeloos, and C. N. A. Trotman (Boca Raton: CRC Press), 1-19.

Monod, J. (1971). Chance and Necessity: An Essay on the Natural Philosophy of Modern Biology. Paris: Ed. du Seuil.

Muñoz, J., Gómez, A., Green, A. J., Figuerola, J., Amat, F., and Rico, C. (2008). Phylogeography and local endemism of the native Mediterranean brine shrimp Artemia salina
(Branchiopoda: Anostraca). Mol. Ecol. 17, 3160-3177.

Muñoz, J., Gómez, A., Green, A. J., Figuerola, J., Amat, F., and Rico, C. (2010). Evolutionary origin and phylogeography of the diploid obligate parthenogen Artemia parthenogenetica (Branchiopoda: Anostraca). PLoS ONE 5, el1932. doi:10.1371/journal.pone.0011932

Parraguez, M., Gajardo, G., and Beadmore, J. A. (2009). The New World Artemia species A. franciscana and A. persimilis are highly differentiated for chromosome size and heterochromatin content. Hereditas 146 93-103.

Piersma, T., and van Gils, J. A. (2011). The Flexible Phenotype: A BodyCentred Integration of Ecology, Physiology, and Behavior. Oxford: Oxford University Press.

Pilla, E. J. S., and Beardmore, J. A. (1994). Genetic and morphometric differentiation in Old World bisexual species of Artemia (the brine shrimp). Heredity, 73, 47-56.

Qiu, J. (2008). The third pole. Nature 454, 393-396.

Rabkin, J. G., and Struening, E. L. (1976). Life events, stress, and illness. Science 194, 1013-1020.

Rode, N. O., Charmantier, A., and Lenormand, T. (2011). Male-female co evolution in the wild: evidence from a time series in Artemia franciscana. Evolution 65, 2881-2892.

Ryan, F. P. (2006). Genomic creativity and natural selection: a modern synthesis. Biol. J. Linn. Soc. Lond. 88 655-672.

Schuler, D., and Conte, G. L. (2009) Genetics and ecological speciation. Proc. Natl. Acad. Sci. U.S.A. 106, 9955-9962.

Shapiro, J. A. (2011). Evolution: A View from the 21st Century. New Jersey: FT Press Science.

Sharon, G., Segal, D., Ringo, J. M. Hefetz, A, Zilber-Rosenberg, I., and Rosenberg, E. (2010). Commensal bacteria play a role in mating preference of Drosophila melanogaster. Proc. Natl. Acad. Sci. U.S.A. 107, 20051-20056.

Staples, J., Reger, J., Feulner, P. G. D. Smadja, C., Galindo, J., Ekblom, R., Bennison, C., and Ball, A. D.
(2010). Adaptation genomics: the next generation. Trends Ecol. Evol. 25, 705-712.

Stenseth, N. C., and Dunlop, E. S. (2009). Unnatural selection. Nature 457, 803-804.

Stern, D. L., and Orgogozo, V. (2009). Is genetic evolution predictable? Science 323, 746-751.

Terradas, J., and Peñuelas, J. (2009). Evolution: much more than genetics. The need for a holistic view. Open Evol. J. 3, 38-45.

Thuiller, W. (2007). Biodiversity - climate change and the ecologist. Nature 448, 550-552.

Trianthaphyllidis, G. V., Abarzopoulos, T. J., and Sorgeloos, P. (1998) Review on the biogeography of the genus Artemia (Crustacea, Anostraca). J. Biogeogr. 25, 213-226.

Van Stappen, G. (2002). "Zoogeography," in Artemia: Basic and Applied Biology, eds Th. J. Abatzopoulos, J. A. Beardmore, J. S. Clegg, and P. Sorgeloos (Dordrecht: Kluwer Academic Publishers) 171-224.

Wharton, D. (2007). Life at the Limits. Organisms in Extreme Environments. Cambridge: Cambridge University Press.

Conflict of Interest Statement: The authors declare that the research was conducted in the absence of any commercial or financial relationships that could be construed as a potential conflict of interest.

Received: 16 March 2012; accepted: 19 May 2012; published online: 22 June 2012.

Citation: Gajardo GM and Beardmore JA (2012) The brine shrimp Artemia: adapted to critical life conditions. Front. Physio. 3:185. doi: 10.3389/fphys.2012.00185

This article was submitted to Frontiers in Fractal Physiology, a specialty of Frontiers in Physiology.

Copyright (c) 2012 Gajardo and Beardmore. This is an open-access article distributed under the terms of the Creative Commons Attribution Non Commercial License, which permits noncommercial use, distribution, and reproduction in other forums, provided the original authors and source are credited. 